\title{
The Role of Attitudes and Ethicality on Branded Video Games (Advergames) Acceptance
}

\author{
By Joaquin Aldas-Manzano* \\ José Martí-Parreño$$
\text { Carla Ruiz-Mafe }
$$$$
\text { Lisa Scribner }
$$

\begin{abstract}
Advergames are branded video games that blur the line between entertainment and advertising. Advergames are gaining momentum among advertisers and advertising agencies fueled by their capability to engage teenagers and young adults with branded communications. This study focuses on consumers' intentions to use advergames analyzing three attitudinal factors - attitude toward advertising, attitude toward product placement in video games, and attitude toward advergames- and the ethical evaluations of the use of advergames as an advertising format (ethicality). The proposed model was empirically tested using a sample of 304 college students. Major findings suggest that attitudes toward advergames increase playing intentions of advergames and ethical concerns significantly worsen attitudes toward advergame.
\end{abstract}

\section{Introduction}

Advergames have been defined as "a videogame designed around a brand" (Wise et al., 2008) and deserve special attention within branded entertainment formats (Okazaki \& Yaguie, 2012). Branded entertainment implies the insertion of a brand within an entertainment property in such a way that the line between entertainment and advertising becomes blurred. Advergames are playing an increasingly important role in marketing communication plans as a way to target and engage with young audiences (Terlutter \& Capella, 2013). Advertisers' interest in advergaming reflects itself in a growing expenditure on advergames within marketing communication budgets and the expectation is for a continued expansion of these efforts going forward. Scholars' interest in advergames is also increasing as proved by the Journal of Advertising devoting a special issue on the topic in 2013. The growing interest of advertisers and advertising agencies in advergames is fueled by their capability to engage teenagers and young adults (Peters and Leshner, 2013). The interest of

\footnotetext{
*Associate Professor of Marketing, Universitat de València, Valencia, Spain.

${ }^{\dagger}$ Associate Professor of Marketing, Universidad Europea de Valencia, Valencia, Spain.

†Associate Professor of Marketing, Universitat de València, Valencia, Spain.

Associate Professor of Marketing, University of North Carolina - Wilmington, USA.
} 
important players in the advertising field such as Young \& Rubicam and Starcom Media on advergames is big enough to warrant their own advergaming divisions (IGDA, 2008). Advertising in video games will reach $\$ 7.2$ billion by 2016 while advergames are expected to account for about $78 \%$ of total game advertising revenue (DCF Intelligence, 2011). While advergames' effects on consumers' memory and attitude toward the brand placed in the video game have been studied (Marti et al., 2013) little attention has been paid to consumers' behavioral intention to use advergames or to the factors contributing to those intentions. This study focuses on consumers' intentions to use advergames analyzing three attitudinal factors - attitude toward advertising, attitude toward product placement in video games, and attitude toward advergames- and the ethical evaluations of the use of advergames as an advertising format (ethicality).

\section{Advergames as Hybrid Messages: The Role of Attitudes and Ethicality}

Advergames can be considered as hybrid messages. Hybrid messages "include all paid attempts to influence audiences for commercial benefit using communications that project a non- commercial character" (Balasubramanian, 1994:30). Advergames use video games to place brands and products with commercial purposes. Advergames can be classified in three different levels based on the way brands or products are placed in them (Chen \& Ringel, 2001). For associative advergames the product and/or the brand is linked to a particular activity (e.g., a sport or a leisure activity like a quest) featured in the advergame. For illustrative advergames the brand or product itself plays a significant role in the game play (e.g., in Oreo Adventure the player can pick up Oreo cookies while moving through the jungle in order to get extra points or bonuses). The third level - demonstrative advergames - allows the player to experience the product in its natural context as reproduced in the gaming environment. In BMW M3 Challenge the player gets a simulation of driving a real BMW car model. Video games and advergames are different marketing communications tools. The main difference between product placement in video games and advergames is that while product placement uses existing video games -or future video games- which are developed by an independent third party, advergames are totally funded and controlled by the marketer that pays for the branded video game to be developed (the advergame). The very nature of advergames as hybrid messages creates some controversy. On the one hand advergames offer consumers free entertainment. Advergames can be played online or downloaded for free from the brand's website (e.g., www.nabiscoworld.com) or even from online video games' websites. On the other hand, consumers should not be aware of the persuasive attemps advergames represent. As with product placement (Balasubramanian, Karrh \& Patwardham, 2006) ethical concerns arise when using advergames as a marketing communications tool. So both attitudes and ethical evaluations (ethicality) are expected to affect consumers' intentions to use advergames. 


\section{Attitude toward Advergames and Intention to use}

Attitude is an individual's positive or negative evaluation of a given object or behavior (Ajzen, 1991) and includes feelings and/or affective responses. Attitude refers to the individual's general willingness to engage in a given behavior. Therefore, a positive attitude towards advergames leads to favorable evaluations and predispositions toward playing with them. Ajzen \& Fishbein's (1980) Theory of Reasoned Action provides a consistent framework of the relationships between individuals' attitudes and their behavioral intentions. This theory assumes that people consciously choose to perform or not to perform a specific behavior based on their own attitudes and relevant social others' attitudes toward the given attitudinal object. Prior studies show that attitude has a direct, positive effect on behavioral intentions (Davis et al 1989; Limayem, Khalifa \& Frini, 2000). Therefore, the following hypothesis is posited:

H1: the better the attitude toward advergames the greater the intention to use advergames

\section{Attitude toward Advertising}

Attitude toward advertising has been considered a main factor in advertising success and is a contributing factor to attitude toward the advergames (Lutz, 1985). Attitude toward advertising in general can influence attitude toward advergames because of its hybrid nature of editorial content (the video game itself) and advertising content (the brands placed in the video game). Festinger's Cognitive Dissonance Theory (1957) can help to establish the link between attitude toward advertising in general and attitude toward advergames. According to this theory individuals try to keep a balance in their cognitive system adapting dissonances which offer lesser resistance to change to be consistent with previous attitudes on the system. Because consumers are less familiar with a novel advertising format like advergames they can try to adapt their behavior toward advergames -as an advertising format- using previous attitudes toward advertising in general. Broadly speaking, attitude toward advergames can be considered dependent on attitude toward advertising in general. In fact, Poels, Janssens \& Herrewijn (2013) posit general attitude toward advertising is positively related to attitude towards in-game advertising. Hence, the following hypothesis is posited:

$\mathrm{H} 2$ : a negative attitude toward advertising in general will decrease a positive attitude toward advergames.

\section{Attitude toward Product Placement in Video Games}

Product (brand) placement refers to "the practice of including a brand name product, package, signage or other trademark merchandise within a motion picture, television or other media vehicles for increasing the memorability of the brand and for instant recognition at the point of purchase" (Panda, 2004, p. 42). The literature suggests different consumer responses to 
product placement in video games. On the one hand, consumers report that brands placed in video games can enhance realism (Nelson, Keum \& Yaros, 2004), and playing experience (Chaney, Lin \& Chaney, 2004). On the other hand, brands placed in video games can elicit feelings of intrusion (Hernández et al., 2004) and players' concerns about being influenced by brands without being conscious of it. Because advergames contain brands with commercial purposes it is expected that there is an effect of consumers' attitudes toward product placement in video games on consumers' attitudes toward advergames. There is also expected to be an effect of attitude toward advertising in general on attitude toward product placement in video games based on Festinger's Cognitive Dissonance Theory (1957). Previous research found a strong correspondence between attitudes toward advertising and attitudes toward product placement (Gupta, Balasubramanian \& Klassen, 2000). Therefore, the following hypotheses are posited:

H3: a positive attitude toward product placement in video games will increase a positive attitude toward advergames.

H4: a negative attitude toward advertising in general will increase a negative attitude toward product placement in video games.

\section{Ethicality}

The presence of products or brands in media content (e.g., movies, tv shows) with commercial purposes must deal with the ethicality framework associate to levels of both disguise and obtrusiveness. Disguise messages refer to advertising in which the sponsor is not clearly identified and obtrusive messages refers to advertising secondary to the main stimulus perceived by an audience (i.e., a movie, a video game). The ethic acceptability of product placement has attracted considerable media and research attention (Balasubramanian, Karrh \& Patwardham, 2006) especially related to ethically charged products such as tobacco or guns (Gould, Gupta \& Grabner-Kräuter, 2000; McKechnie \& Zou, 2003). Because advergames -as hybrid messagescan be considered as delivering both disguised and obtrusive messages, consumers' ethical concerns are expected to influence attitude toward advergames. The same rationale applies to the relationship between consumers' ethical concerns and attitude toward product placement in video games. Therefore, the following hypotheses are posited:

H5: the higher the consumers' ethical concerns about using video games to promote products or brands placed in them, the worst the attitude to advergames.

H6: the higher the consumers' ethical concerns about using video games to promote products or brands placed in them, the worst the attitude toward product placement in video games.

Figure 1 depicts the research model as an outcome of the literature review presented above. 
Figure 1. Conceptual Model and proposed Hypotheses

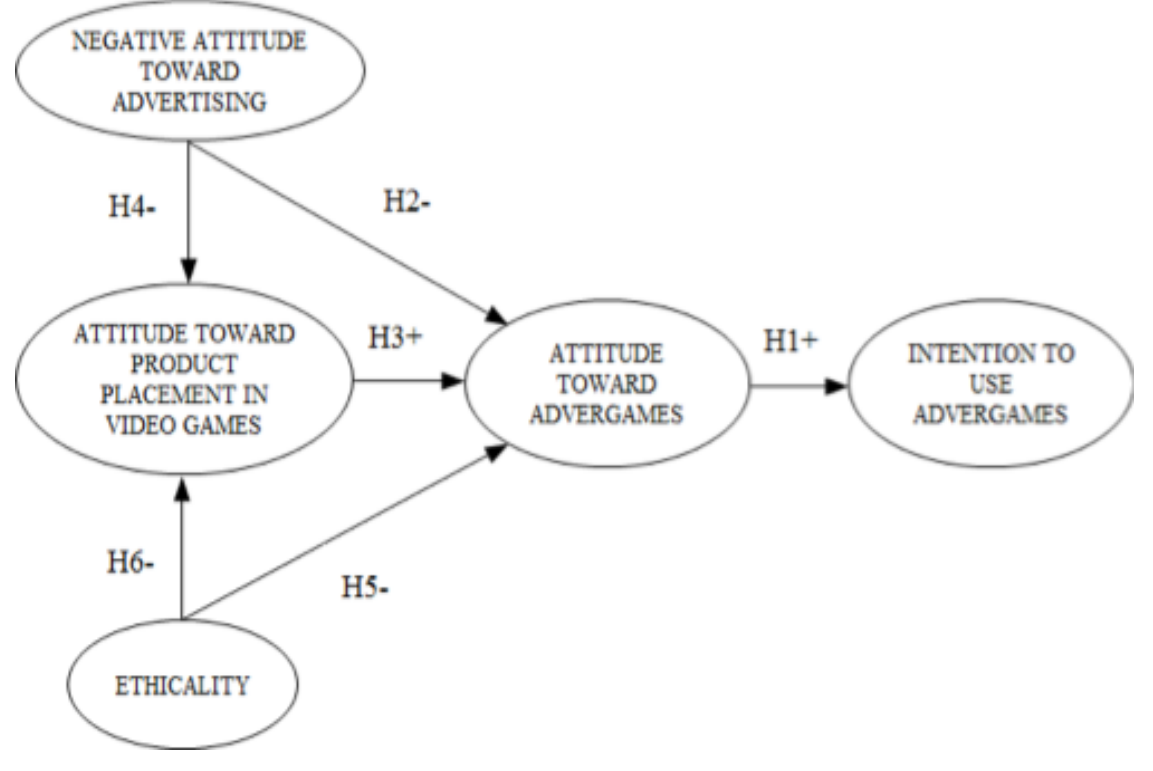

\section{Method and Sample}

A questionnaire was developed to empirically test the proposed research model on a final sample of 304 college students from a large State University in the southeast coast of the United States selected on a convenience basis. This particular sample was studied given that previous studies reported $70 \%$ of college students play video games (Peters \& Leshner, 2013). The average age of our respondents was 21.3 years and $52.6 \%$ of them were males. The measurement instrument was developed using previously tested scales: attitude toward advertising (Winkler \& Buckner, 2006); attitude toward advergames was adapted from Taylor \& Todd (1995); attitude toward product placement in video games based on (Nelson, 2002); ethicality based on Lord \& Gupta (2010) and Hudson, Hudson \& Peloza (2008) and intention to use advergames based on Taylor \& Todd (1995). Measurement model was evaluated in terms of reliability, convergent and discriminant validity.

\section{Method and Sample}

The proposed conceptual model was tested (Figure 1) using structural equation modelling with EQS 6.2 software (Bentler, 1995). The empirical estimates for the main-effects model and model goodness of fit indexes are shown in Table 1 . The results indicate a good fit of the data to our conceptual model $(\mathrm{S}-\mathrm{B} \chi 2=157.33, \mathrm{df}=97, \mathrm{p}<.01 ; \mathrm{RMSEA}=.046 ; \mathrm{NFI}=.928 ; \mathrm{TLI}=.964$; $\mathrm{CFI}=.971$ ). Our model confirms that attitude toward advergames increases playing intention $(\mathrm{H} 1 ; \beta=0.448 ; \mathrm{p}<.01)$. As hypothesized, a negative attitude towards advertising makes people have a worse attitude toward advergames 
$(\mathrm{H} 2 ; \beta=-0.141 ; \mathrm{p}<.05)$ but has no impact in the attitude toward product placement in this format $(\mathrm{H} 4 ; \beta=-0.032 ; \mathrm{p}>.05)$. That variable, attitude toward product placement in video games is a strong determinant of attitude toward advergames $(\mathrm{H} 3 ; \beta=0.298 ; \mathrm{p}<.01)$. Ethical concerns about product placement in video games significantly worsens attitudes toward advergames in general $(\mathrm{H} 5 ; \beta=-0.206 ; \mathrm{p}<.01)$ and attitude toward product placement in video games $(\mathrm{H} 6 ; \beta=-0.124 ; \mathrm{p}<.05)$

Table 1. Hypotheses Testing

\begin{tabular}{|c|c|c|c|}
\hline Hyphotesis & Description & $\begin{array}{l}\text { Standardized } \\
\text { beta }\end{array}$ & $\begin{array}{l}\text { Robust t } \\
\text { value }\end{array}$ \\
\hline $\mathrm{H} 1$ & Attitude toward advergames-->Intention to use advergames & $0,448 * *$ & 6,612 \\
\hline $\mathrm{H} 2$ & Attitude toward advertising-->Attitude toward advergames & $-0,141 *$ & $-2,137$ \\
\hline H3 & Attitude toward product placement in video games-->Attitude toward advergame: & $0,298 * *$ & 4,357 \\
\hline $\mathrm{H} 4$ & Attitude toward advertising-->Attitude toward product placement in video games & $-0,032$ & $-0,032$ \\
\hline H5 & Ethicality-->Attitude toward advergames & $-0,206 * *$ & $-3,262$ \\
\hline H6 & Ethicality-->Attitude toward product placement in video games & $-0,124 *$ & 1,961 \\
\hline
\end{tabular}

\section{Discussion and Conclusion}

This research contributes to increase our knowledge of the antecedents of consumers' intentions to use advergames. Results suggest that attitudes and ethical concerns play a main role in consumers' intentions to use advergames. Regarding attitudes advertisers should try to increase positive attitudes toward advergames (e.g., educating consumers about the benefits of advergames: free entertainment, non-intrusive advertising...) in order to assure consumers acceptance and use. The fact that attitude toward advertising has no effect on attitude toward product placement in video games suggests that consumers may not clearly identify product placement as a persuasive tool. Nevertheless consumers' ethical concerns about using video games as a promotional tool has an effect on both attitude toward advergames and the presence of brands and products for commercial purposes in video games, suggesting that advertisers should be careful when trying to use advergames as "advertising in disguise". On the contrary, consumers should be properly informed about the goals of advergames so they could freely choose to get involved in advertising messages in an entertainment-based context through video games. Regarding limitations, culture moderates ethical concerns on product placement (Gould, Gupta \& Grabner-Kräuter, 2000) so future research should test the proposed model on a cross-cultural framework. Future research should also explore other factors such as utilitarian and hedonic perceived value of advergames on consumers' intentions to use advergames. Because men and women behave different when using advergames (e.g., men and women differ in video game genres preferences) the moderating role of gender should also be analyzed. 


\section{References}

Ajzen, I. 1991. The theory of planned behavior. Organ Behav Hum Dec, 50, 2, 179211. DOI=http://dx.doi.org/10.1016/0749-5978(91)90020-T

Ajzen, I. \& Fishbein, M. 1980. Understanding Attitudes and Predicting Social Behaviour. Prentice-Hall, Englewood Cliffs, NJ.

Balasubramanian, S.K. 1994. Beyond advertising and publicity: hybrid messages and public policy issues. $J$ Advertising, 23, 4, 29-46. DOI=10.1080/00913367.1943. 10673457

Balasubramanian, S.K., Karrh, J.A. and Patwardhan, H. 2006. Audience Response to Product Placements: An Integrative Framework and Future Research Agenda. $J$ Advertising, 35, 3, 115-141. DOI=10.2753/JOA0091-3367350308

Bentler, P.M. 1995. EQS structural equations program manual. Multivariate Software Inc, Encino, CA.

Chaney, I., Lin, K.H. \& Chaney, J. 2004. The Effect of Billboards within the Gaming Environment. Journal of Interactive Advertising, 5, 1, 37-45. DOI=10.1080/ 15252019.2004.10722092

Chen, J. \& Ringel, M. 2001. Can advergaming be the future of interactive advertising? Available from http://www.locz.com.br/loczgames/advergames.pdf

Davis, F. D., Bagozzi, R. P., \& Warshaw, P. R. 1989. User acceptance of computer technology: a comparison of two theoretical models. Manage Sci, 35, 8, 9821003. DOI $=10.1287 / \mathrm{mnsc} .35 .8 .982$

DCF Intelligence 2011. DFC Intelligence Forecasts Global Advertising in Video Games to Reach \$7.2 billion in 2016. Press release, September 13, 2011. Available from http://www.dfcint.com/wp/?p=315

Festinger, L. 1957. A Theory of Cognitive Dissonance. Stanford University Press, Stanford, CA.

Gould, S.J. Gupta, P. B. \& Grabner-Kräuter, S. 2000. Product Placements in Movies: A Cross-Cultural Analysis of Austrian, French and American Consumer's Attitudes Toward This Emerging International Promotion Medium. J Advertising, 29, 4, 41-58. DOI=10.1080/00913367.2000.10673623

Gupta, P. B., Balasubramanian, S.K. \& Klassen, M. 2000. Viewers' Evaluations of Product Placements in Movies: Public Policy Issues and Managerial Implications. Journal of Current Issues and Research in Advertising, 22, 2, 41-52. DOI=10. 1080/10641734.2000.10505107

Hernández, M.D., Chapa, S., Minor, M.S., Maldonado, C. \& Barranzuela, F. 2004. Hispanic attitudes toward advergames: a proposed model of their antecedents. Journal of Interactive Advertising, 5, 1, 74-83.

Hudson, S. Hudson, D. \& Peloza, J. 2008. Meet the Parents: A Parents' Perspective on Product Placement in Children's Films. $J$ Bus Ethics, 80, 289-304. DOI=10.1007/s10551-007-9421-5

IGDA (International Games Developers Association) 2008. Casual Games White Paper, Available from http://www.igda.org/casual/IGDA_CasualGames_White paper_2008.pdf

Limayem, M., Khalifa, M., \& Frini, A. 2000. What makes consumers buy from Internet? A longitudinal study of online shopping. Systems, Man and Cybernetics, Part A: Systems and Humans, IEEE Transactions on, 30 (4), 421432.

Lord, K. R. \& Gupta, P. B. 2010. Response of buying-center participants to B2B product placements. $J$ Bus Ind Mark, 25, 3, 188-195. DOI=10.1108/088586210 11027777 
Lutz, R.J. 1985. Affective and Cognitive Antecedents of Attitude Toward the Ad: A Conceptual Framework. In Alwitt, L. \& Mitchell, A. (Eds.). Psychological Processes and Advertising Effects. Lawrence J. Eribaum, Hillsdale, NJ, 45-65.

Martí, J., Aldás, J., Currás, R. \& Sánchez, I. 2013. Factors Contributing Brand Attitude in Advergames: Entertainment and Irritation. J Brand Manag, 20, 5, 374-388. DOI=10.1057/bm.2012.22

McKechnie, S.A. \& Zhou, J. 2003. Product Placement in Movies: A Comparison of Chinese and American Consumers' Attitudes. Int J Advert, 22, 349-374.

Nelson, M.R. (2002). Recall of brand placements in computer/video games. $J$ Advertising Res, 42, 2, 80-92.

Nelson, M.R., Keum, H. and Yaros, R.A. 2004. Advertainment or Adcreep? game players' attitudes toward advertising and product placements in computer games. Journal of Interactive Advertising, 5, 1, 3-21.

Okazaki, S. \& Yagüe, M. J. 2012. Responses to an advergaming campaign on a mobile social networking site: An initial research report. Comput Hum Behav, 28, 1, 78-86. DOI=10.1016/j.chb.2011.08.013

Panda, T.K. 2004. Effectiveness of product placements in Indian films and its effects on brand memory and attitude with special reference to Hindi films. The ICFAI Journal of Marketing Management, August, 42-56.

Peters, S. \& Leshner, G. 2013. Get in the Game: The Effects of Game-Product Congruity and Product Placement Proximity on Game Players' Processing of Brands Embedded in Advergames. $J$ Advertising, 42, 2-3, 113-130. DOI=10. 1080/00913367.2013.774584

Poels, K., Janssens, W. \& Herrewijn, L. 2013. Play Buddies or Space Invaders? Players' Attitudes Toward In-Game Advertising. J Advertising, 42, 2-3, 204-218. DOI $=10.1080 / 00913367.2013 .774600$

Taylor, S. \& Todd, P. 1995. Understanding information technology usage: a test of competing models. Inform Syst Res, 6, 2, 144-176. DOI=http://dx.doi.org/10. 1287/isre.6.2.144

Terlutter, R., \& Capella, M. L. 2013. The Gamification of Advertising: Analysis and Research Directions of In-Game Advertising, Advergames, and Advertising in Social Network Games. J Advertising, 42, 2-3, 95-112. DOI=10.1080/00913367. 2013.774610

Winkler, T. \& Buckner, K. 2006. Receptiveness of gamers to embedded brand messages in advergames: attitudes towards product placement. Journal of Interactive Advertising, 7, 1, 24-32.

Wise, K., Bolls, P.D., Kim, H., Venkataraman, A. \& Meyer, R. 2008. Enjoyment of advergames and brand attitudes: the impact of thematic relevance. Journal of Interactive Advertising, 9, 1, 27-36. 